\title{
Dendritic Cell Immune Therapy to Break or Induce Tolerance
}

\author{
Giada Amodio $^{1} \cdot$ Andrea Annoni $^{1} \cdot$ Silvia Gregori ${ }^{1}$
}

Published online: 11 September 2015

(C) Springer International Publishing AG 2015

\begin{abstract}
Dendritic cells (DCs) represent the key regulator of the immune system. The particular milieu in which DCs encounter the antigen together with their intrinsic properties defines their ability to promote an active or a tolerogenic immune response. The development of protocols to differentiate in vitro immunogenic or tolerogenic DCs opened the possibility to employ them as cell therapy in a list of immunemediated diseases. While a number of clinical trials with immunogenic DCs have proven the safety and the efficacy of the therapy, only few studies have been performed with tolerogenic DCs. In this review, we will discuss major obstacles encountered, and strategies applied, to improve the efficacy of DC-based immunotherapies including lentiviral vector-based approaches.
\end{abstract}

Keywords Dendritic cells · Immunotherapy · Tolerance · Lentiviral vectors

This article is part of the Topical Collection on Cellular Therapies: Preclinical and Clinical

Silvia Gregori

gregori.silvia@hsr.it

Giada Amodio

amodio.giada@hsr.it

Andrea Annoni

annoni.andrea@hsr.it

San Raffaele Telethon Institute for Gene Therapy (TIGET), Division of Regenerative Medicine, Stem Cells and Gene Therapy, IRCCS

San Raffaele Scientific Institute, Via Olgettina, 58,

20132 Milan, Italy

\section{Introduction}

Dendritic cells (DCs) are a heterogeneous population of cells recognized as the most powerful antigen-presenting cells (APCs). DCs are present in lymphoid and non-lymphoid tissues and continuously patrol the body as immature precursors seeking for foreign invaders (antigen (Ag)s), whether these are bacteria, viruses, or dangerous toxins. After capturing Ags, DCs travel to lymph nodes or the spleen, where they undergo maturation, up-regulate co-stimulatory molecules, and acquire the ability to activate $\mathrm{T}$ and B cells [1]. Since their discovery, accumulated evidences sustain the central role of DCs in immunity induction, and more recently, it has become evident that DCs play an important role in maintaining tissue homeostasis and in promoting tolerance. The latter function is mediated by DCs in steady state or by specialized subsets of DCs, named tolerogenic DCs [2-4].

A large body of reports indicates the presence of different DC subtypes characterized by specialized functions and by the expression of homing receptors, which allow them to reside in specific tissue. In humans, two major and intrinsically different subpopulations of DCs have been identified: the myeloid and the plasmacytoid DCs. Myeloid DCs are a component of the adaptive immune system and are activated upon Ag encounter in the periphery, whereas plasmacytoid DCs belong to the innate immune system and upon interaction with nucleic acids secrete type 1 interferons. Each of these subsets is defined by the expression of a set of markers and specific functions and can be activated by different cytokines [5, 6]. Myeloid and plasmacytoid DCs can be either immunogenic, able to induce an active immune response, or tolerogenic that control immune responses through several mechanisms, including inhibition of effector $\mathrm{T}$ cells and induction of apoptosis or of $\mathrm{T}$ regulatory (Treg) cells (reviewed in [7-9]). 
The prominent role of DCs in promoting $\mathrm{T}$ cell activation or tolerance is the rationale for DC-based immunotherapy for cancer and infectious diseases [10], or for immune-mediated diseases [11, 12], respectively. The identification of a method to differentiate a large number of DCs in vitro from monocyte precursors using granulocyte-macrophage colony-stimulating factor (GM-CSF) and interleukin (IL)-4 [13] pioneered the application of DC-based therapies. While a number of clinical-grade protocols for DC differentiation for cancer immunotherapy have been established and DC-based immunotherapies have been tested in clinical settings (reviewed in $[14 \bullet]$ ), culture conditions for the generation of tolerogenic DCs have only recently been defined [2-4].

In this review, we will give an overview of the state of the art, of still unsolved issues (i.e., the identification of route and time of administration), and of new strategies for a safe and effective DC-based immunotherapy.

\section{Biology of DCs and Its Impact on Designing DC-Based Immunotherapy}

Designing DC-based immunotherapy for cancer, viral infections, as well as for autoimmunity and allergy, implies comprehension of DC biology. To promote immunity and tolerance, DCs should present Ags to T cells in complex with MHC molecules (signal 1). Signal 1 per se does not activate $\mathrm{T}$ cells for a productive response, but drives T cells into anergy or cell death, two important mechanisms involved in maintaining peripheral tolerance $[15,16]$. To support efficient $\mathrm{T}$ cell activation and clonal expansion, DCs should provide costimulation (signal 2). A number of different co-stimulatory pathways can be expressed by DCs: some are immunogenic (i.e., CD80-CD86/CD28, CD40/CD40L) and others are inhibitory (i.e., CD80/CTLA-4, PD-L1/PD-1) [17-20]. These arrays of $\mathrm{DC} / \mathrm{T}$ cell interactions determine the level of $\mathrm{T}$ cell activation: when pro-immunogenic interactions prevail, $\mathrm{T}$ cells become effectors; on the contrary, when inhibitory interactions predominate, $\mathrm{T}$ cells may acquire regulatory activity, become anergic or exhausted cells, or undergo apoptosis. An additional signal is provided by the cytokine milieu present at the time of T cell priming (signal 3) and drives the specialization of the Ag-specific response toward T helper (Th) (Th1, Th2, Th17) or regulatory (FOXP3 ${ }^{+}$Tregs, Th3, Treg type 1 ( $\operatorname{Tr} 1)$ cells [21-25]. Moreover, DCs sense mediators of innate immunity and discriminate the nature of the encountered pathogen by expressing cytokine receptors (in particular interferon receptors), Fc receptors, CD40, lectins, and toll-like receptors (TLRs), which trigger signaling cascades able to settle DC responses toward innate or adaptive immunity [26, 27].

The downstream effects of the integration of all the abovementioned signals converge to few intracellular signaling pathways: (i) nuclear factor-kB (NF-kB), (ii) mitogen- activated protein kinases (MAPK) [28], and (iii) interferon regulatory factors (IRF) [29]. The NF-KB family (homo- or heterodimeric complexes formed by combinations of five subunits: p65/RelA, RelB, c-Rel, p50, and p52) plays a crucial role in immunity and inflammation by activating genes encoding for pro-inflammatory cytokines and chemokines (IL-6, IL-12, TNF $\alpha$, MIP-1 $\alpha$, MCP1) [30]. The NF-kB pathway is regulated by negative feedback mechanisms involving several inhibitory molecules (IkB, A20, TRIM), which prevent excessive inflammation and autoimmunity [31-35]. MAPKs are serine/threonine kinases that regulate multiple cellular processes, including immune responses [36]. MAPKs comprise the extracellular signal-regulated protein kinases (ERK) [37, 38], the c-Jun N-terminal kinases (JNK), a component of AP-1, a transcription factor that transactivates many pro-inflammatory genes [39, 40], and the p38 stressactivated protein kinases (p38) [41, 42]. ERK is involved in DC survival [43], in regulation of inflammation, and in immune suppression associated with IL-10 release [44]. p38 plays an important part in DC maturation, being involved in the up-regulation of co-stimulatory molecules and activation markers, and in IL- $1 \beta$, TNF $\alpha$, IL- 6 , and IL-12 secretion [45-47]. Moreover, during the last decade, it has become clear that microRNAs (miR), a class of non-coding 20-22 nucleotides long RNAs, are involved in controlling DC activation. DCs derived from miR $-155^{-/-}$mice showed a reduced ability to stimulate Ag-specific proliferation [48], and miR-155 and miR-146a expression is induced in human and murine macrophages and DCs upon lipopolysaccharide (LPS) stimulation, demonstrating that these miRNAs are involved in the regulation of TLR signaling [49-52]. Overall, these evidences suggest that enhancement or inhibition of individual signaling pathways could generate either immunogenic or immunosuppressive DCs.

\section{Immunotherapy in Cancer}

The efficacy of DC-based immunotherapy in cancer relies on three major goals: (i) induction of tumor-specific effector $\mathrm{T}$ cell responses, (ii) inhibition of Treg cell expansion and/or function, and (iii) generation of a pool of tumor-specific memory $\mathrm{T}$ cells to control cancer relapse. The definition of protocols to in vitro generate powerful DCs is therefore of primarily importance. Several methods to differentiate DCs starting from $\mathrm{CD} 14^{+}$monocytes or $\mathrm{CD} 34^{+}$cells have been established. The vast majority of clinical trials have been performed using autologous $\mathrm{CD} 14^{+}$monocytes cultured in vitro with GM-CSF and IL-4, matured with different proinflammatory cytokine cocktails, and loaded with tumor peptides or lysates (reviewed in [53]). To obtain high numbers of cells, CD34 ${ }^{+}$cells from granulocyte (G)-CSF-mobilized peripheral blood of patients have been used as alternative 
sources of DC precursors [54, 55]. Repetitive administrations of $\mathrm{CD} 34^{+}$-derived autologous DCs in cancer patients were able to induce systemic tumor-specific immune responses in the absence of major side effects $[54,55]$. More recently, the use of allogeneic cord blood CD $34^{+}$cells has been considered as alternative to autologous $\mathrm{CD} 34^{+}$cells. Despite the encouraging results in obtaining high numbers of functional DCs that contain few contaminants, the need of long-term culture to generate CD34-derived DCs represents a limitation for their clinical use [56-58].

Since the first clinical trial in B cell lymphoma [59], DCbased immunotherapy has been tested for the treatment of different malignancies, including melanoma, prostatic cancer, glioma, and renal cell cancer $[10,14 \bullet]$. Overall, the limited immunogenicity of administered DCs resulted in a weak induction of tumor-specific $\mathrm{T}$ cells and elicited clinical responses only in a fraction of patients $[60,61]$. To overcome this drawback, much effort has been made over the years, and three major approaches have been exploited and implemented: (i) the identification of the best tumor-associated $\mathrm{Ag}$ (TAA) to load DCs, (ii) the improvement of Ag loading to induce tumor-specific immune response, and (iii) the selection of the optimal activation stimulus and route of DC administration. By definition, tumors are not homogeneous tissues and the expression of TAAs is not uniform neither for a given type of tumor nor between primary tumors and metastases. For this reason, since the first clinical trial performed in melanoma patients, DCs were loaded with cocktails of TAAs derived from tumor lysate [55, 62]. Although tumor biopsy is not always possible, the use of tumor lysate to load DCs has been adopted in following trials [53, 63, 64]. Tumor lysate, in addition to providing a large panel of TAAs, allows Ag processing and presentation in the contest of HLA class I and class II molecules, thus promoting both $\mathrm{CD} 4^{+}$and $\mathrm{CD} 8^{+} \mathrm{T}$ cell responses $[65,66]$. Recently, to improve TAA loading and presentation by DCs, tumor processing in oxidative or hypoxic conditions has been implemented [67, 68]. In pre-clinical models of glioma and breast carcinoma, it has been shown that the administration of DCs loaded with lysates obtained in hypoxic conditions increased $\mathrm{CD} 8^{+} \mathrm{T}$ cell responses and the rate of apoptotic tumor cells [67]. Moreover, promising results have been obtained in a pilot study of five subjects with recurrent ovarian cancer, in whom immunotherapy with DC loaded with the abovementioned procedure was well tolerated and promoted a potent anti-tumor T cell response [68].

One of the critical issues of cancer immunotherapy with DCs is their relatively low ability to reach the draining lymph nodes [10]; therefore, the improvement of DC migration has been considered to enhance the efficacy of the vaccine. One interesting approach is to induce the expression of C-C chemokine receptor type 7 (CCR7) on differentiated DCs. It has been shown that addition of prostaglandin E (PGE2) to the cytokine cocktail used to mature monocyte-derived DCs promoted CCR7 up-regulation [69] and enhanced DCs' homing capacity to tumor-draining lymph nodes [70]. Thus far, to achieve a rapid dissemination in different tissues, the majority of DC products have been administered intravenously. However, as discussed above, the limited ability of infused cells to reach tumor-draining lymph nodes, together with the fact that intravenously injected cells are primarily trapped in the liver and lungs, prompted investigators to identify different routes of DC administration including intradermal, subcutaneous, intra-nodal, and intra-tumor delivery [71]. For intradermal or subcutaneous injection, a rapid migration to the regional lymph nodes has been proven; however, this strategy requires the delivery of a high number of DCs in a small volume, which can affect cell viability [70, 72]. Alternatively, intra-nodal injection has been proposed; however, this method raises some concerns regarding the accessibility of tumor-draining lymph nodes and the potential damage of the lymph node [62, 70, 73].

In conclusion, optimizing Ag loading and activation of DCs, and the identification of the more suitable route of DC administration are warranted to generate potent immunotherapeutic DC-based vaccines.

\section{DCs as Tolerogenic Cell Product}

The discovery that DCs play an important role in modulating immune responses and in inducing tolerance introduced the use of in vitro-generated tolerogenic DCs as cell therapy to regulate immune responses in immune-mediated diseases [11, 12]. The vast majority of protocols developed to generate in vitro tolerogenic DCs for clinical purposes have in common the use of monocyte-derived DCs differentiated in the presence of GM-CSF and IL-4 in combination with cytokines, or pharmacological agents, or immunosuppressive drugs (reviewed in [2]). A general consensus for the phenotype and function of in vitro-generated tolerogenic DCs is that they should express low levels of co-stimulatory molecules and high IL-10/IL-12 production ratio. Nevertheless, it is becoming evident that, according to the differentiation protocol used, tolerogenic DCs acquired different immune modulatory properties by up-regulating a variety of inhibitory molecules [74, 75.] and the ability to promote the induction of a specific subset of Tregs [7, 11]. Despite the number of pre-clinical studies demonstrating feasibility and efficacy of tolerogenic DC immunotherapy [76-81], and the efforts dedicated to developing methods to generate clinical-grade tolerogenic DCs [75•, 82], only a limited number of clinical trials have been performed or planned [2, 12, 82].

To define the optimal tolerogenic DCs to be used in vivo, recently studies comparing different subpopulations of in vitrodifferentiated tolerogenic DCs have been performed [74, 75•]. Stability, cytokine production profile, and suppressive activity 
of tolerogenic DCs have been compared, and results indicated that IL-10-modulated mature DCs are the best-suited cells for tolerogenic DC-based therapies. Our group contributed to the identification of IL-10 as key factor for promoting the differentiation of potent tolerogenic DCs. We set up a protocol to differentiate tolerogenic DCs, named DC-10, from peripheral blood monocytes cultured in the presence of GM-CSF, IL-4, and IL-10 [24]. Despite the presence of IL-10 during differentiation, DC-10 are mature myeloid cells that express CD86 and HLA-DR. DC-10 also express the tolerogenic molecules immunoglobulin-like transcript (ILT)2, ILT3, ILT4, and HLA-G [24]. The high expression levels of HLA-G and the high IL-10/IL-12 production ratio render DC-10 potent inducers of allo-specific $\operatorname{Tr} 1$ cells $[24,83]$. The clinical use of DC-10 relies on this latter feature, and clinical-grade protocols for the induction of allo-specific $\operatorname{Tr} 1$ cells, suitable for cell therapy, using DC-10 have been developed [84, 85]. In addition to this clinical application, we are currently testing the potential use of DC-10 as cell therapy for tolerogenic DCbased approaches $[7,11]$.

Autologous monocyte-derived DCs rendered tolerogenic by the treatment with anti-sense oligonucleotides targeting CD40, CD80, and CD86 have been used in the first tolerogenic DC-based clinical trial [86]. This phase I study assessed the safety of repetitive intradermal administration of tolerogenic DCs in adult type 1 diabetes (T1D) patients. A second phase I study has been conducted in rheumatoid arthritis (RA) patients treated with a single intradermal injection of autologous DCs cultured with an inhibitor of (NF- $\mathrm{kB}$ ) signaling (BAY 11-7082) and pulsed with citrullinated peptides [87]. Both treatments were safe and well tolerated and paved the way to developing clinical studies to test the efficacy of tolerogenic DC immunotherapy in T1D and RA and after kidney transplantation. A phase II clinical trial to treat T1D patients at onset with autologous anti-sense oligonucleotide-treated DCs has been launched (ClinicalTrials.gov identifier: NCT02354911). Moreover, based on encouraging results obtained in pre-clinical models [88], a clinical trial with autologous DCs rendered tolerogenic by the exposure to dexamethasone and vitamin D3, activated with monophosphoryl lipid, and loaded with synovial fluids to treat RA patients has been designed (AUTODECRA, ClinicalTrials.gov identifier: NCT01352858) [12]. In this study, tolerogenic DCs will be injected intra-articularly in order to induce a local immune suppression and increase their homing to draining lymph nodes [12].

Under the umbrella of The ONE Study (The ONE Study. http://www.onestudy.org/), an integrated European Unionfounded project, the first clinical trial testing tolerogenic DCs to prevent organ rejection has been recently started (The ONE Study ATDC Trial, ONEatDC, ClinicalTrials.gov Identifier: NCT02252055). In this study, autologous tolerogenic DCs differentiated with low doses of GM-CSF in the absence of IL-4 (tol-DCs) will be administered to living-donor renal transplant recipients [89]. The efficacy of tol-DC treatment will be compared to that of other immunosuppressive cells (ex vivo-isolated and in vitro-expanded polyclonal or allo-specific FOXP $3^{+}$Tregs, Tr1 cells, and regulatory macrophages (Mregs)) [90-92].

Results from these studies will confirm the safety and define the efficacy of tolerogenic DC-based therapy in restoring tolerance in autoimmune diseases and in preventing graft rejection.

\section{Genetically Modified DC Immune Therapy to Break or Induce Tolerance}

DC-based vaccination for cancer or persistent infections is aimed at inducing or reactivating immune responses and implies the presentation of the target Ag by activated DCs. Ag presentation is a requirement also for "negative" vaccination to dampen immune reactions. As alternative to tumor lysate loading, one of the approaches used to promote immunogenic DCs for cancer immunotherapy is the delivery of TAAs by viral vectors, which are ensuring stable and prolonged $\mathrm{Ag}$ expression and presentation. Lentiviral vectors (LVs) efficiently transduce human DCs [93-97] and induce strong and durable anti-tumor T cell responses [98-100]. Moreover, LVmediated DC transduction does not result in major changes in the state of DC activation [101-103], supporting the possibility to exploit LV-mediated stable and efficient Ag presentation to generate immunogenic or tolerogenic DCs. In this section, we will discuss the use of LVs as a tool to genetically modify DCs for immunogenic and tolerogenic DC-based therapies.

LV-mediated transduction of DCs to achieve T cell priming with TAAs has been largely explored in vitro. Overall, results showed the potential ability of DCs transduced with LV encoding for TAAs to generate tumor-specific $\mathrm{CD}^{+}$and $\mathrm{CD}^{+} \mathrm{T}$ cells [98]. $\mathrm{CD} 8^{+} \mathrm{T}$ cells play a major role in cancer eradication [104]; however, $\mathrm{CD}^{+} \mathrm{T}$ cell response is crucial for sustaining CTL effector functions and for inducing a memory response in vivo $[105,106]$. Priming of $\mathrm{CD}^{+} \mathrm{T}$ cells by LVtransduced DCs occurs only if the LV-encoded Ag has access to an MHC class II presentation pathway. To this aim, Rowe et al. [107] developed LVs encoding for the C-terminal of the invariant chain (Ii) fused with ovalbumin (OVA) (LV.IiOVA) that allow the presentation of OVA in the contest of MHC class II. Results showed that LV-IiOVA-transduced DCs efficiently promote the induction of both OVA-specific $\mathrm{CD}^{+}$and $\mathrm{CD}^{+} \mathrm{T}$ cells and that in vivo delivery of LV.IiOVA protects mice from developing OVA-expressing EG7 tumor. Improvement in efficacy of tumor eradication may derive from the expression of multiple TAAs in order to overcome the mechanism of tumor escape due to the loss of TAA expression. 
Direct in vivo LV administration to transduce DCs offers some advantages: it does not require cell manipulation, and the vector itself triggers acute inflammation providing an adjuvant effect; however, it cannot offer high specificity of cell targeting. Conversely, the in vitro LV-mediated DC transduction can significantly improve safety by minimizing off-target transduction and by the limited life span of transferred cells. Moreover, administering in vitro LV-transduced DCs allows repetitive cell administration. LV-mediated gene transfer to express modulators of activation pathways in DCs has been explored as adjuvant to design efficacious cancer immunotherapies. To this purpose, Akazawa et al. [108] overexpressed the major TLR adaptor molecules (MyD88, TRIF/TICAM-1) in mouse DCs and demonstrated that MyD88-modified DCs secrete IL-6 and IL-12p40, whereas TICAM-1-modified DCs induce IFN $\alpha$ production and CD86 up-regulation. These LV-modified DCs increased allogeneic responses in vitro and in vivo in a mouse model of syngeneic tumor implant and delayed tumor growth [108]. Andreakos et al. [109] showed that the LV-mediated overexpression of NF-KB inducing kinase (NIK) increased DC activation and their ability to promote a transgene-specific Th1 response. Analogously, Breckpot et al. [110] showed that LV-mediated expression of short hairpin (sh)RNA specific for A20, a zinc finger protein that negatively regulates TNF receptor and TLR-mediated signaling, resulted in increased and sustained production of IL-6, IL-10, and IL-12p70 by human DCs. A20 down-regulated DCs skewed naive $\mathrm{CD}^{+} \mathrm{T}$ cells toward IFN $\gamma$-producing Th1 cells and have an enhanced capacity to prime Melan-A/MART-1-specific $\mathrm{CD} 8^{+} \mathrm{T}$ cells. A further example acting on the NF-kB pathway comes from Tao et al. [111], who demonstrated that silencing of RelB expression in bone marrow-derived DCs (BMDCs), mediated by LV carrying RelB shRNA, resulted in low IL-12 secretion and co-stimulatory molecule expression. Interestingly, shRNA RelB-DCs significantly inhibited allogeneic $\mathrm{T}$ cell responses, down-regulated Th1 cytokine production, and promoted Th2 cytokines. Escors et al. [112] performed a comprehensive study on signaling pathways governing functional plasticity of DCs using LVs simultaneously encoding for an $\mathrm{Ag}$, to stimulate $\mathrm{CD} 8^{+}$and $\mathrm{CD} 4^{+} \mathrm{T}$ cell responses, together with constitutively activated factors of the three main MAPK and IFN induction pathways, including p38 and ERK for MAKP, and JNK1 and interferon regulatory factor-3 (IRF3) for the IFN pathway. Results indicated that the activation of p38 in DCs, and to a lesser extent, of JNK1 promotes DC maturation leading to increased OVA-specific immunity, which resulted in tumor regression in vivo. Conversely, activation of ERK in DCs induced the expression TGF- $\beta$, and the expression of a constitutively activated IRF3 stimulated IL-10 secretion by DCs. The concomitant activation of ERK and IRF3 suppressed the immune response and stimulated Treg cell expansion [112]. More recently, Arce et al. [113] successfully applied this strategy and using LV-transduced DCs suppressed experimental inflammatory arthritis.

The over-expression of immune regulatory molecules, such as IL-10, ILT3, and vasoactive intestinal peptide (VIP), has been proposed as an alternative approach to generate tolerogenic DCs. LV-mediated over-expression of IL-10 converted BMDCs in tolerogenic DCs that upon in vivo transfer prevent allergic contact dermatitis [114]. Human $\mathrm{CD} 4^{+}$cells transduced with LV encoding ILT3, and differentiated into DCs, displayed reduced allo-stimulatory capacity and the ability to promote $\mathrm{FOXP}^{+}$Tregs in vitro. Furthermore, a single inoculation of myelin oligodendrocyte glycoprotein (MOG)35-55-pulsed BMDCs engineered to express VIP in experimental autoimmune encephalomyelitis (EAE) mice resulted in protection from disease development [115]. Alternative candidates to confer tolerogenic properties to DCs via LV gene transfer are indoleamine 2,3-dioxygenase (IDO1), a tryptophan catabolizing enzyme, regulator of immunity in several physiopathologic conditions, IL-4, and TGF $\beta$ [116-119].

An interesting and innovative approach to generate potent tolerogenic DCs is targeting the Ag expression and presentation to DCs at the immature state. The genetic modification of BM cells with a LV encoding for an Ag under the control of DC-STAMP promoter resulted in stable and persistent output of DCs expressing and presenting the Ag at the steady state that generate Ag-specific tolerance in RIP-OVA mice [120]. Similarly, in vivo transfer of LV.DC-STAMP.MOG transduced DCs prevented EAE progression [121]. Alternatively, $\mathrm{Ag}$ expression and presentation by DCs at immature steady state can be obtained by expressing the Ag under the posttranscriptional negative regulation mediated by those miRNAs, which are up-regulated in DCs upon activation. Brown et al. [122] showed that the addition of miR155specific target sequences at the $3^{\prime}$ untranslated region of LV expression cassette allowed a significant reduction of GFP expression as consequence of a TLR-driven activation.

Overall, the efficacy of LV-mediated gene transfer into DCs and their precursors offers several clinically applicable opportunities to exploit functional plasticity of DCs to design specific immunotherapies both for tolerance induction in autoimmunity and transplants, and for immunity to cancer and persistent infectious.

\section{Conclusions}

Significant progress has been made in understanding how DC immunotherapy can mediate immunity or promote tolerance and how DCs can be generated and manipulated in vitro in order to improve their immunogenicity or their tolerogenicity. The feasibility, the safety, and the effectiveness of immunotherapy with immunogenic DCs have been repetitively 
demonstrated. Conversely, only recently the safety and the efficacy of immunotherapy with tolerogenic DCs have been demonstrated in pre-clinical models and in patients. These results supported the development of further clinical trials in cancer and infectious disease for immunogenic DCs and in autoimmunity and transplantation for tolerogenic DCs. However, several questions remain to be addressed to optimize immunotherapy: the selection of the optimal route of administration, the stability and the lifespan of the infused cells, and the identification of biomarkers of efficacy. During the last years, a number of consortia are investing efforts to identify hurdles for DC-based immunotherapies. SITC Immune Biomarkers Task is now investigating how to improve immunotherapy in cancer (http://www. sitcancer.org/about-sitc/general-society/committees/biomarkerstask-force) while the action BM1305: Action to Focus and Accelerate Cell-based Tolerance-inducing Therapies (www. afactt.eu), under the umbrella of the European Cooperation in the field of Scientific and Technical Research (COST) action, is working to establish minimal requirements to define a tolerogenic DCs, and to identify shared and disease-specific biomarkers of tolerance in patients undergoing tolerogenic DC-based therapies. At the same time, a deep knowledge on DC biology, together with advances in LV-mediated gene transfer, gave the possibility to improve the tolerogenic potential and the stability of DCs by inducing the constitutive expression of tolerogenic molecules.

Acknowledgments This work was supported by grants to S.G. from the Italian Telethon Foundation (TGT11E02) and from the COST Action BM1305 A FACTT (www.afactt.eu) supported by COST (European Cooperation in Science and Technology). COST is part of the EU Framework Programme Horizon 2020.

\section{Compliance with Ethics Guidelines}

Conflict of Interest Giada Amodio, Andrea Annoni, and Silvia Gregori declare that they have no conflict of interest.

Human and Animal Rights and Informed Consent This article does not contain any studies with human or animal subjects performed by any of the authors.

\section{References}

Papers of particular interest, published recently, have been highlighted as:

- Of importance

1. Banchereau J, Steinman RM. Dendritic cells and the control of immunity. Nature. 1998;392(6673):245-52.

2. Morelli AE, Thomson AW. Tolerogenic dendritic cells and the quest for transplant tolerance. Nat Rev Immunol. 2007;7(8):610-21.

3. Matta BM, Castellaneta A, Thomson AW. Tolerogenic plasmacytoid DC. Eur J Immunol. 2010;40(10):2667-76.
4. Steinbrink K, Mahnke K, Grabbe S, et al. Myeloid dendritic cell: from sentinel of immunity to key player of peripheral tolerance? Hum Immunol. 2009;70(5):289-93.

5. MacDonald KP, Munster DJ, Clark GJ, et al. Characterization of human blood dendritic cell subsets. Blood. 2002;100(13): 4512-20.

6. Larregina AT, Falo Jr LD. Changing paradigms in cutaneous immunology: adapting with dendritic cells. J Investig Dermatol. 2005; 124(1):1-12

7. Gregori S. Dendritic cells in networks of immunological tolerance. Tissue Antigens. 2011;77(2):89-99.

8. Amodio G, Gregori S. Dendritic cells a double-edge sword in autoimmune responses. Front Immunol. 2012;3:233.

9. Thomson AW. Tolerogenic dendritic cells: all present and correct? Am J Transplant. 2010;10(2):214-9.

10. Figdor CG, de Vries IJ, Lesterhuis WJ, et al. Dendritic cell immunotherapy: mapping the way. Nat Med. 2004;10(5):475-80.

11. Amodio G, Gregori S. Human tolerogenic DC-10: perspectives for clinical applications. Transplant Res. 2012;1(1):14.

12. Hilkens CM, Isaacs JD. Tolerogenic dendritic cell therapy for rheumatoid arthritis: where are we now? Clin Exp Immunol. 2013;172(2):148-57.

13. Sallusto F, Lanzavecchia A. Efficient presentation of soluble antigen by cultured human dendritic cells is maintained by granulocyte/macrophage colony-stimulating factor plus interleukin 4 and downregulated by tumor necrosis factor alpha. J Exp Med. 1994;179(4):1109-18.

14. Anguille S, Smits EL, Lion E, et al. Clinical use of dendritic cells for cancer therapy. Lancet Oncol. 2014;15(7):e257-67. A summary on the effectiveness of dendritic cell-based cancer immunotherapy.

15. Roncarolo MG, Levings MK, Traversari C. Differentiation of T regulatory cells by immature dendritic cells. J Exp Med. 2001;193(2):F5-9.

16. Jeon MS, Atfield A, Venuprasad K, et al. Essential role of the E3 ubiquitin ligase Cbl-b in T cell anergy induction. Immunity. 2004;21(2):167-77.

17. Chiang YJ, Kole HK, Brown K, et al. Cbl-b regulates the CD28 dependence of T-cell activation. Nature. 2000;403(6766):216-20.

18. Freeman GJ, Long AJ, Iwai Y, et al. Engagement of the PD-1 immunoinhibitory receptor by a novel B7 family member leads to negative regulation of lymphocyte activation. J Exp Med. 2000;192(7):1027-34.

19. Janeway Jr CA, Bottomly K. Signals and signs for lymphocyte responses. Cell. 1994;76(2):275-85.

20. Sansom DM. CD28, CTLA-4 and their ligands: who does what and to whom? Immunology. 2000;101(2):169-77.

21. Chen W, Jin W, Hardegen N, et al. Conversion of peripheral CD4+ CD25- naive $\mathrm{T}$ cells to $\mathrm{CD} 4+\mathrm{CD} 25+$ regulatory $\mathrm{T}$ cells by TGFbeta induction of transcription factor Foxp3. J Exp Med. 2003;198(12):1875-86.

22. Celli S, Garcia Z, Bousso P. CD4 T cells integrate signals delivered during successive DC encounters in vivo. J Exp Med. 2005;202(9):1271-8.

23. Kapsenberg ML, Hilkens CM, Wierenga EA, et al. The paradigm of type 1 and type 2 antigen-presenting cells. Implications for atopic allergy. Clin Exp Allergy. 1999;29 Suppl 2:33-6.

24. Gregori S, Tomasoni D, Pacciani V, et al. Differentiation of type $1 \mathrm{~T}$ regulatory cells $(\mathrm{Tr} 1)$ by tolerogenic DC-10 requires the IL-10dependent ILT4/HLA-G pathway. Blood. 2010;116(6):935-44.

25. Levings MK, Sangregorio R, Galbiati F, et al. IFN-alpha and IL10 induce the differentiation of human type $1 \mathrm{~T}$ regulatory cells. J Immunol. 2001;166(9):5530-9.

26. Caparros E, Munoz P, Sierra-Filardi E, et al. DC-SIGN ligation on dendritic cells results in ERK and PI3K activation and modulates cytokine production. Blood. 2006;107(10):3950-8. 
27. Pasare C, Medzhitov R. Toll-dependent control mechanisms of CD4 T cell activation. Immunity. 2004;21(5):733-41.

28. Luft T, Rodionova E, Maraskovsky E, et al. Adaptive functional differentiation of dendritic cells: integrating the network of extraand intracellular signals. Blood. 2006;107(12):4763-9.

29. Coccia EM. IFN regulation and functions in myeloid dendritic cells. Cytokine Growth Factor Rev. 2008;19(1):21-32.

30. Ghosh S, Karin M. Missing pieces in the NF-kappaB puzzle. Cell. 2002;109(Suppl):S81-96.

31. Kawai T, Akira S. Signaling to NF-kappaB by toll-like receptors. Trends Mol Med. 2007;13(11):460-9.

32. Coornaert B, Carpentier I, Beyaert R. A20: central gatekeeper in inflammation and immunity. J Biol Chem. 2009;284(13): 8217-21.

33. Barisic S, Strozyk E, Peters N, et al. Identification of PP2A as a crucial regulator of the NF-kappaB feedback loop: its inhibition by UVB turns NF-kappaB into a pro-apoptotic factor. Cell Death Differ. 2008;15(11):1681-90.

34. Bowie AG. TRIM-ing down tolls. Nat Immunol. 2008;9(4): 348-50.

35. Shi M, Deng W, Bi E, et al. TRIM30 alpha negatively regulates TLR-mediated NF-kappa B activation by targeting TAB2 and TAB3 for degradation. Nat Immunol. 2008;9(4):369-77.

36. Ardeshna KM, Pizzey AR, Devereux S, et al. The PI3 kinase, p38 SAP kinase, and NF-kappaB signal transduction pathways are involved in the survival and maturation of lipopolysaccharidestimulated human monocyte-derived dendritic cells. Blood. 2000;96(3):1039-46.

37. Boulton TG, Cobb MH. Identification of multiple extracellular signal-regulated kinases (ERKs) with antipeptide antibodies. Cell Regul. 1991;2(5):357-71.

38. Boulton TG, Nye SH, Robbins DJ, et al. ERKs: a family of protein-serine/threonine kinases that are activated and tyrosine phosphorylated in response to insulin and NGF. Cell. 1991;65(4):663-75.

39. Derijard B, Hibi M, Wu IH, et al. JNK1: a protein kinase stimulated by UV light and Ha-Ras that binds and phosphorylates the cJun activation domain. Cell. 1994;76(6):1025-37.

40. Kyriakis JM, Banerjee P, Nikolakaki E, et al. The stress-activated protein kinase subfamily of c-Jun kinases. Nature. 1994;369(6476):156-60.

41. Lee JC, Laydon JT, McDonnell PC, et al. A protein kinase involved in the regulation of inflammatory cytokine biosynthesis. Nature. 1994;372(6508):739-46.

42. Han J, Lee JD, Bibbs L, et al. A MAP kinase targeted by endotoxin and hyperosmolarity in mammalian cells. Science. 1994;265(5173):808-11.

43. Rescigno M, Martino M, Sutherland CL, et al. Dendritic cell survival and maturation are regulated by different signaling pathways. J Exp Med. 1998;188(11):2175-80.

44. Agrawal A, Dillon S, Denning TL, et al. ERK1-/- mice exhibit Th1 cell polarization and increased susceptibility to experimental autoimmune encephalomyelitis. J Immunol. 2006;176(10):5788-96.

45. Arrighi JF, Rebsamen M, Rousset F, et al. A critical role for $\mathrm{p} 38$ mitogen-activated protein kinase in the maturation of human blood-derived dendritic cells induced by lipopolysaccharide, TNF-alpha, and contact sensitizers. J Immunol. 2001;166(6): 3837-45.

46. Yu Q, Kovacs C, Yue FY, et al. The role of the p38 mitogenactivated protein kinase, extracellular signal-regulated kinase, and phosphoinositide-3-OH kinase signal transduction pathways in CD40 ligand-induced dendritic cell activation and expansion of virus-specific $\mathrm{CD} 8+\mathrm{T}$ cell memory responses. J Immunol. 2004;172(10):6047-56.
47. Lu HT, Yang DD, Wysk M, et al. Defective IL-12 production in mitogen-activated protein (MAP) kinase kinase 3 (Mkk3)-deficient mice. EMBO J. 1999;18(7):1845-57.

48. Rodriguez A, Vigorito E, Clare S, et al. Requirement of bic/ microRNA-155 for normal immune function. Science. 2007;316(5824):608-11.

49. Taganov KD, Boldin MP, Chang KJ, et al. NF-kappaB-dependent induction of microRNA miR-146, an inhibitor targeted to signaling proteins of innate immune responses. Proc Natl Acad Sci U S A. 2006;103(33):12481-6.

50. Ceppi M, Pereira PM, Dunand-Sauthier I, et al. MicroRNA-155 modulates the interleukin-1 signaling pathway in activated human monocyte-derived dendritic cells. Proc Natl Acad Sci U S A. 2009;106(8):2735-40.

51. Jin P, Han TH, Ren J, et al. Molecular signatures of maturing dendritic cells: implications for testing the quality of dendritic cell therapies. J Transl Med. 2010;8:4.

52. Holmstrom K, Pedersen AW, Claesson MH, et al. Identification of a microRNA signature in dendritic cell vaccines for cancer immunotherapy. Hum Immunol. 2010;71(1):67-73.

53. Palucka K, Banchereau J. Cancer immunotherapy via dendritic cells. Nat Rev Cancer. 2012;12(4):265-77.

54. Mackensen A, Herbst B, Chen JL, et al. Phase I study in melanoma patients of a vaccine with peptide-pulsed dendritic cells generated in vitro from $\mathrm{CD} 34(+)$ hematopoietic progenitor cells. Int $\mathbf{J}$ Cancer. 2000;86(3):385-92.

55. Banchereau J, Palucka AK, Dhodapkar M, et al. Immune and clinical responses in patients with metastatic melanoma to CD34(+) progenitor-derived dendritic cell vaccine. Cancer Res. 2001;61(17):6451-8.

56. Cany J, Dolstra H, Shah N. Umbilical cord blood-derived cellular products for cancer immunotherapy. Cytotherapy. 2015;17(6):739-48.

57. Balan S, Kale VP, Limaye LS. A simple two-step culture system for the large-scale generation of mature and functional dendritic cells from umbilical cord blood CD34+ cells. Transfusion. 2009;49(10):2109-21.

58. Harada Y, Okada-Nakanishi Y, Ueda Y, et al. Cytokine-based high log-scale expansion of functional human dendritic cells from cordblood CD34-positive cells. Sci Rep. 2011;1:174.

59. Hsu FJ, Benike C, Fagnoni F, et al. Vaccination of patients with Bcell lymphoma using autologous antigen-pulsed dendritic cells. Nat Med. 1996;2(1):52-8.

60. Palucka K, Banchereau J, Mellman I. Designing vaccines based on biology of human dendritic cell subsets. Immunity. 2010;33(4): 464-78.

61. Draube A, Klein-Gonzalez N, Mattheus S, et al. Dendritic cell based tumor vaccination in prostate and renal cell cancer: a systematic review and meta-analysis. PLoS One. 2011;6(4): e18801.

62. Nestle FO, Alijagic S, Gilliet M, et al. Vaccination of melanoma patients with peptide- or tumor lysate-pulsed dendritic cells. Nat Med. 1998;4(3):328-32.

63. Palucka AK, Ueno H, Connolly J, et al. Dendritic cells loaded with killed allogeneic melanoma cells can induce objective clinical responses and MART-1 specific CD8+ T-cell immunity. J Immunother. 2006;29(5):545-57.

64. Holtl L, Rieser C, Papesh C, et al. Cellular and humoral immune responses in patients with metastatic renal cell carcinoma after vaccination with antigen pulsed dendritic cells. J Urol. 1999;161(3):777-82.

65. Berard F, Blanco P, Davoust J, et al. Cross-priming of naive CD8 $\mathrm{T}$ cells against melanoma antigens using dendritic cells loaded with killed allogeneic melanoma cells. J Exp Med. 2000;192(11):1535-44. 
66. Holtl L, Zelle-Rieser C, Gander H, et al. Immunotherapy of metastatic renal cell carcinoma with tumor lysate-pulsed autologous dendritic cells. Clin Cancer Res. 2002;8(11):3369-76.

67. Olin MR, Andersen BM, Zellmer DM, et al. Superior efficacy of tumor cell vaccines grown in physiologic oxygen. Clin Cancer Res. 2010;16(19):4800-8.

68. Chiang CL, Kandalaft LE, Tanyi J, et al. A dendritic cell vaccine pulsed with autologous hypochlorous acid-oxidized ovarian cancer lysate primes effective broad antitumor immunity: from bench to bedside. Clin Cancer Res. 2013;19(17):4801-15.

69. Luft T, Jefford M, Luetjens $P$, et al. Functionally distinct dendritic cell (DC) populations induced by physiologic stimuli: prostaglan$\operatorname{din} \mathrm{E}(2)$ regulates the migratory capacity of specific DC subsets. Blood. 2002;100(4):1362-72.

70. De Vries IJ, Krooshoop DJ, Scharenborg NM, et al. Effective migration of antigen-pulsed dendritic cells to lymph nodes in melanoma patients is determined by their maturation state. Cancer Res. 2003;63(1):12-7.

71. Butterfield LH. Dendritic cells in cancer immunotherapy clinical trials: are we making progress? Front Immunol. 2013;4:454.

72. Morse MA, Coleman RE, Akabani G, et al. Migration of human dendritic cells after injection in patients with metastatic malignancies. Cancer Res. 1999;59(1):56-8.

73. Jonuleit $\mathrm{H}$, Giesecke-Tuettenberg A, Tuting $\mathrm{T}$, et al. A comparison of two types of dendritic cell as adjuvants for the induction of melanoma-specific T-cell responses in humans following intranodal injection. Int J Cancer. 2001;93(2):243-51.

74. Naranjo-Gomez M, Raich-Regue D, Onate C, et al. Comparative study of clinical grade human tolerogenic dendritic cells. J Transl Med. 2011;9:89.

75. Boks MA, Kager-Groenland JR, Haasjes MS, et al. IL-10-generated tolerogenic dendritic cells are optimal for functional regulatory $\mathrm{T}$ cell induction-a comparative study of human clinical-applicable DC. Clin Immunol. 2012;142(3):332-42. The first study comparing GMP protocols to obtain tolerogenic DC for clinical use.

76. Adorini L. Tolerogenic dendritic cells induced by vitamin D receptor ligands enhance regulatory $\mathrm{T}$ cells inhibiting autoimmune diabetes. Ann N Y Acad Sci. 2003;987:258-61.

77. Chorny A, Gonzalez-Rey E, Fernandez-Martin A, et al. Vasoactive intestinal peptide induces regulatory dendritic cells with therapeutic effects on autoimmune disorders. Proc Natl Acad Sci U S A. 2005;102(38):13562-7.

78. Popov I, Li M, Zheng X, et al. Preventing autoimmune arthritis using antigen-specific immature dendritic cells: a novel tolerogenic vaccine. Arthritis Res Ther. 2006;8(5):R141.

79. Bonham CA, Peng L, Liang X, et al. Marked prolongation of cardiac allograft survival by dendritic cells genetically engineered with NF-kappa B oligodeoxyribonucleotide decoys and adenoviral vectors encoding CTLA4-Ig. J Immunol. 2002;169(6):3382-91

80. Horibe EK, Sacks J, Unadkat J, et al. Rapamycin-conditioned, alloantigen-pulsed dendritic cells promote indefinite survival of vascularized skin allografts in association with $\mathrm{T}$ regulatory cell expansion. Transpl Immunol. 2008;18(4):307-18.

81. Raimondi G, Sumpter TL, Matta BM, et al. Mammalian target of rapamycin inhibition and alloantigen-specific regulatory $\mathrm{T}$ cells synergize to promote long-term graft survival in immunocompetent recipients. J Immunol. 2010;184(2):624-36.

82. Kalantari T, Kamali-Sarvestani E, Ciric B, et al. Generation of immunogenic and tolerogenic clinical-grade dendritic cells. Immunol Res. 2011;51(2-3):153-60.

83. Amodio G, Comi M, Tomasoni D, et al. HLA-G expression levels influence the tolerogenic activity of human DC-10. Haematologica. 2015;100(4):548-57.

84. Bacchetta R, Gregori S, Serafini G, et al. Molecular and functional characterization of allogantigen-specific anergic $\mathrm{T}$ cells suitable for cell therapy. Haematologica. 2010;95(12): 2134-43.

85. Petrelli A, Mfarrej BG, et al. Generation of donor-specific t regulatory type 1 cells from patients on dialysis for cell therapy after kidney transplantation. Transplantation. 2015.

86. Giannoukakis N, Phillips B, Finegold D, et al. Phase I (safety) study of autologous tolerogenic dendritic cells in type 1 diabetic patients. Diabetes Care. 2011;34(9):2026-32.

87. Thomas R. Dendritic cells and the promise of antigenspecific therapy in rheumatoid arthritis. Arthritis Res Ther. 2013;15(1):204.

88. Stoop JN, Harry RA, von Delwig A, et al. Therapeutic effect of tolerogenic dendritic cells in established collagen-induced arthritis is associated with a reduction in Th17 responses. Arthritis Rheum. 2010;62(12):3656-65.

89. Moreau A, Varey E, Bouchet-Delbos L, et al. Cell therapy using tolerogenic dendritic cells in transplantation. Transplant Res. 2012;1(1):13.

90. Geissler EK, The ONE. Study compares cell therapy products in organ transplantation: introduction to a review series on suppressive monocyte-derived cells. Transplant Res. 2012;1(1):11.

91. Hutchinson JA, Geissler EK. Now or never? The case for cellbased immunosuppression in kidney transplantation. Kidney Int. 2015;87(6):1116-24.

92. Leslie M. Immunology. Regulatory T cells get their chance to shine. Science. 2011;332(6033):1020-1.

93. Schroers R, Sinha I, Segall H, et al. Transduction of human PBMC-derived dendritic cells and macrophages by an HIV-1based lentiviral vector system. Mol Ther. 2000;1(2):171-9.

94. Dyall J, Latouche JB, Schnell S, et al. Lentivirus-transduced human monocyte-derived dendritic cells efficiently stimulate antigen-specific cytotoxic T lymphocytes. Blood. 2001;97(1): 114-21.

95. Breckpot K, Corthals J, Heirman C, et al. Activation of monocytes via the $\mathrm{CD} 14$ receptor leads to the enhanced lentiviral transduction of immature dendritic cells. Hum Gene Ther. 2004;15(6):562-73.

96. Zarei S, Leuba F, Arrighi JF, et al. Transduction of dendritic cells by antigen-encoding lentiviral vectors permits antigen processing and MHC class I-dependent presentation. J Allergy Clin Immunol. 2002;109(6):988-94.

97. Dullaers M, Breckpot K, Van Meirvenne S, et al. Side-by-side comparison of lentivirally transduced and mRNA-electroporated dendritic cells: implications for cancer immunotherapy protocols. Mol Ther. 2004;10(4):768-79.

98. Breckpot K, Dullaers M, Bonehill A, et al. Lentivirally transduced dendritic cells as a tool for cancer immunotherapy. J Gene Med. 2003;5(8):654-67.

99. Metharom P, Ellem KA, Wei MQ. Gene transfer to dendritic cells induced a protective immunity against melanoma. Cell Mol Immunol. 2005;2(4):281-8.

100. He Y, Zhang J, Mi Z, et al. Immunization with lentiviral vectortransduced dendritic cells induces strong and long-lasting $\mathrm{T}$ cell responses and therapeutic immunity. J Immunol. 2005;174(6): 3808-17.

101. Gruber A, Kan-Mitchell J, Kuhen KL, et al. Dendritic cells transduced by multiply deleted HIV-1 vectors exhibit normal phenotypes and functions and elicit an HIV-specific cytotoxic Tlymphocyte response in vitro. Blood. 2000;96(4):1327-33.

102. Tan PH, Beutelspacher SC, Xue SA, et al. Modulation of human dendritic-cell function following transduction with viral vectors: implications for gene therapy. Blood. 2005;105(10):3824-32.

103. Rossetti M, Gregori S, Hauben E, et al. HIV-1-derived lentiviral vectors directly activate plasmacytoid dendritic cells, which in turn induce the maturation of myeloid dendritic cells. Hum Gene Ther. 2011;22(2):177-88. 
104. Boon T, van der Bruggen P. Human tumor antigens recognized by T lymphocytes. J Exp Med. 1996;183(3):725-9.

105. Bonehill A, Heirman C, Thielemans K. Genetic approaches for the induction of a CD4+ T cell response in cancer immunotherapy. $\mathrm{J}$ Gene Med. 2005;7(6):686-95.

106. Bonehill A, Heirman C, Tuyaerts S, et al. Messenger RNAelectroporated dendritic cells presenting MAGE-A3 simultaneously in HLA class I and class II molecules. J Immunol. 2004;172(11):6649-57.

107. Rowe HM, Lopes L, Ikeda Y, et al. Immunization with a lentiviral vector stimulates both CD4 and CD8 T cell responses to an ovalbumin transgene. Mol Ther. 2006;13(2):310-9.

108. Akazawa T, Shingai M, Sasai M, et al. Tumor immunotherapy using bone marrow-derived dendritic cells overexpressing Tolllike receptor adaptors. FEBS Lett. 2007;581(18):3334-40.

109. Andreakos E, Williams RO, Wales J, et al. Activation of NFkappaB by the intracellular expression of NF-kappaB-inducing kinase acts as a powerful vaccine adjuvant. Proc Natl Acad Sci U S A. 2006;103(39):14459-64.

110. Breckpot K, Aerts-Toegaert C, Heirman C, et al. Attenuated expression of A20 markedly increases the efficacy of doublestranded RNA-activated dendritic cells as an anti-cancer vaccine. J Immunol. 2009;182(2):860-70.

111. Qiu T, Zhu HC, Liu XH, et al. Lentiviral-mediated shRNA against RelB induces the generation of tolerogenic dendritic cells. Int Immunopharmacol. 2012;12(3):501-9.

112. Escors D, Lopes L, Lin R, et al. Targeting dendritic cell signaling to regulate the response to immunization. Blood. 2008;111(6): 3050-61.

113. Arce F, Breckpot K, Stephenson H, et al. Selective ERK activation differentiates mouse and human tolerogenic dendritic cells, expands antigen-specific regulatory $\mathrm{T}$ cells, and suppresses experimental inflammatory arthritis. Arthritis Rheum. 2011;63(1):84-95.
114. Besche V, Wiechmann N, Castor T, et al. Dendritic cells lentivirally engineered to overexpress interleukin-10 inhibit contact hypersensitivity responses, despite their partial activation induced by transduction-associated physical stress. J Gene Med. 2010;12(3):231-43.

115. Toscano MG, Delgado M, Kong W, et al. Dendritic cells transduced with lentiviral vectors expressing VIP differentiate into VIP-secreting tolerogenic-like DCs. Mol Ther. 2010;18(5): 1035-45.

116. Bessede A, Gargaro M, Pallotta MT, et al. Aryl hydrocarbon receptor control of a disease tolerance defence pathway. Nature. 2014;511(7508):184-90.

117. Pallotta MT, Orabona C, Bianchi R, et al. Forced IDO1 expression in dendritic cells restores immunoregulatory signalling in autoimmune diabetes. J Cell Mol Med. 2014;18(10):2082-91.

118. Morita Y, Yang J, Gupta R, et al. Dendritic cells genetically engineered to express IL-4 inhibit murine collagen-induced arthritis. J Clin Invest. 2001;107(10):1275-84.

119. Lee WC, Zhong C, Qian S, et al. Phenotype, function, and in vivo migration and survival of allogeneic dendritic cell progenitors genetically engineered to express TGF-beta. Transplantation. 1998;66(12):1810-7.

120. Dresch C, Edelmann SL, Marconi P, et al. Lentiviral-mediated transcriptional targeting of dendritic cells for induction of $\mathrm{T}$ cell tolerance in vivo. J Immunol. 2008;181(7):4495-506.

121. de Andrade PB, Fraefel C, Hilbe M, et al. Transcriptional targeting of DCs with lentiviral vectors induces antigen-specific tolerance in a mouse model of multiple sclerosis. Gene Ther. 2013;20(5):556-66.

122. Brown BD, Gentner B, Cantore A, et al. Endogenous microRNA can be broadly exploited to regulate transgene expression according to tissue, lineage and differentiation state. Nat Biotechnol. 2007;25(12):1457-67. 